\title{
Overexpression of miR-101-2 in donor cells improves the early development of Holstein cow somatic cell nuclear transfer embryos
}

\author{
H. Y. Chang, ${ }^{1,2 *}$ R. X. Xie, ${ }^{1,2 *}$ L. Zhang, ${ }^{1,2 *}$ L. Z. Fu, ${ }^{1,2}$ C. T. Zhang, ${ }^{3}$ H. H. Chen, ${ }^{1,2}$ Z. Q. Wang, ${ }^{1,2}$ Y. Zhang, ${ }^{1,2} \dagger$ \\ and F. S. Quan ${ }^{1,2}+$ \\ ${ }^{1}$ Key Laboratory of Animal Biotechnology of the Ministry of Agriculture, Northwest A\&F University, Yangling 712100, Shaanxi, China, \\ ${ }^{2}$ College of Veterinary Medicine, Northwest A\&F University, Yangling 712100, Shaanxi, China \\ ${ }^{3}$ Animal Husbandry and Veterinary Station of Xining, Xining 810003, Qinghai, China
}

\section{ABSTRACT}

Accumulating studies have suggested that microRNA play a part in regulating multiple cellular processes, such as cell proliferation, apoptosis, the cell cycle, and embryo development. This study explored the effects of miR-101-2 on donor cell physiological status and the development of Holstein cow somatic cell nuclear transfer (SCNT) embryos in vitro. Holstein cow bovine fetal fibroblasts (BFF) overexpressing miR-101-2 were used as donor cells to perform SCNT; then, cleavage rate, blastocyst rate, inner cell mass-to-trophectoderm ratio, and the expression of some development- and apoptosis-related genes in different groups were analyzed. The miR-101-2 suppressed the expression of inhibitor of growth protein 3 (ING3) at mRNA and protein levels, expedited cell proliferation, and decreased apoptosis in $\mathrm{BFF}$, suggesting that ING3, a target gene of miR$101-2$, is a potential player in this process. Moreover, by utilizing donor cells overexpressing miR-101-2, the development of bovine SCNT embryos in vitro was significantly enhanced; the apoptotic rate in SCNT blastocysts was reduced, and the inner cell mass-totrophectoderm ratio and SOX2, POU5F1, and BCL2L1 expression significantly increased, whereas $B A X$ and ING3 expression decreased. Collectively, these findings suggest that miR-101-2 promotes BFF proliferation and vitality, reduces their apoptosis, and improves the early development of SCNT embryos.

Key words: somatic cell nuclear transfer, ING3, apoptosis, embryo development

\footnotetext{
Received May 16, 2018.

Accepted January 22, 2019.

*These authors contributed equally to this work.

$\dagger$ Corresponding authors: zhangyong1956@nwsuaf.edu.cn and quanfusheng@nwsuaf.edu.cn
}

\section{INTRODUCTION}

Since the time the first successful clone, Dolly the sheep, was created, many mammalian species have been successfully cloned by somatic cell nuclear transfer (SCNT; Wakayama et al., 1998; Baguisi et al., 1999; Woods et al., 2003). Somatic cell nuclear transfer technology brings good prospects for propagation of elite genetic merit livestock. Somatic cell nuclear transfer is also a promising technology because of its potential applications in biomedicine (Le et al., 2014). Low efficiency of SCNT clone embryos, however, is a significant barrier to the use of this technology. Many factors have been reported to influence the efficiency of SCNT, of which nuclear donor cells are one of the crucial factors. Tissue specificity, cell type, age, status, and the progression of the cell cycle of donor cells were shown to affect the development of cloned embryos (Inoue et al., 2007).

MicroRNA (miRNA) are small, highly conserved, noncoding RNA that usually suppress gene expression through partially complementary binding to the 3 '-untranslated region (UTR) of target gene mRNA (Luo et al., 2013; Agarwal et al., 2015). Researchers found that decreasing miRNA-145 expression could improve the development of SCNT embryos in vitro ( $\mathrm{Li}$ et al., 2016). Recent reports have also shown that the quality of SCNT embryos was enhanced via using donor cells expressing sperm-borne miR-449b or overexpressing miR-148a (Wang et al., 2017a,b). Furthermore, our previous research demonstrated that miR-125b promotes SCNT-mediated nuclear reprogramming by targeting SUV39H1 (Zhang et al., 2017). These indicated miRNA play a part in the development of SCNT embryos.

We previously analyzed high-throughput sequencing data for differences between cloned and normal in vitro fertilized (IVF) preimplantation embryos (F. S. Quan, unpublished data) and found that miR-101-2 was aberrantly downregulated in cloned embryos compared with the IVF embryos. From a bioinformatics analysis, it is predicted that ING3 is a high-ranking target gene 
of miR-101-2, which was abnormally highly expressed in cloned embryos compared with the IVF embryos. Ubiquitously expressed in mammalian tissues, ING3 is particularly highly expressed in mouse, rhesus monkey, and human oocytes and is one of the candidate oocyte reprogramming factors (Awe and Byrne, 2013). In addition, numerous studies have demonstrated that miR-101 can regulate cell proliferation and apoptosis; it plays different roles in disparate kinds of cells by targeting several genes (Liang et al., 2014; Lin et al., 2014; Zhou et al., 2015). Therefore, it is hypothesized that overexpression of miR-101-2 would enhance the developmental potential of SCNT embryos in vitro.

To test this hypothesis, a stable cell line overexpressing miR-101-2 was established and effects on ING3 expression, progression of the cell cycle, and apoptosis of bovine fetal fibroblasts (BFF) were examined. This stable cell line was subsequently used as a source of nuclear donor cells to produce SCNT embryos, and development rate, total cell numbers, apoptosis-related genes expression, apoptotic rate, and expression of development-related genes were examined.

\section{MATERIALS AND METHODS}

\section{Ethics Statement}

The experimental procedure followed was approved by the Animal Care and Use Committee of Northwest A\&F University, China, and performed in accordance with the animal welfare and ethics guidelines. Bovine ovaries were collected from slaughtered mature cattle at a local abattoir in Xi'An, China. Frozen-thawed spermatozoa were bought from Bright Farming (Shanghai, China).

\section{Reagents}

All chemicals and reagents were purchased from Sigma Aldrich (St. Louis, MO) unless specifically indicated otherwise. Disposable, sterile plastic ware was purchased from Corning (Corning, NY).

\section{Experiment Design}

The experiments undertaken will be briefly outlined in this section, and the details of each of the procedures undertaken will be described in the sections that follow. Experiment 1 was performed to determine whether miR-101-2 targets ING3. Experiment 2 was performed to determine whether miR-101-2 overexpression affects donor cell status and expression of ING3, TP53, $C D K N 1 A, B A X$, and BCL2L1 mRNA. Experiment
3 was performed to measure the miR-101-2 expression in 2-cell, 8-cell, and Day-7 blastocysts from IVF, 513-B1-nuclear transfer (513-B1-NT; SCNT embryos produced using $\mathrm{BFF}$ transfected with empty vectors as donor cells), and miR-101-NT (SCNT embryos produced by using BFF with miR-101-2 overexpression as donor cells) treatments. Experiment 4 was performed to examine the effects of miR-101-2 overexpression on the quality of SCNT embryos and the expression of key developmental genes.

\section{Cell Isolation and Culture}

The BFF were established from the bovine fetal back skin tissue of approximately 90-d-old Holstein cow fetuses (Pan et al., 2015). Briefly, fetal skin tissue samples were rinsed several times with PBS containing penicillin and streptomycin and then minced into $1-\mathrm{mm}^{3}$ pieces. Tissues were cultivated for 1 to $2 \mathrm{wk}$ in 60-mm Petri dishes (Corning) containing Dulbecco's modified Eagle's medium/F12 high-glucose (Invitrogen, Carlsbad, CA) medium supplemented with $10 \%$ fetal bovine serum (FBS; Gibco, Grand Island, NY), 100 $\mathrm{mg} / \mathrm{mL}$ of streptomycin, and $100 \mathrm{IU} / \mathrm{mL}$ of penicillin, in saturation humidity with $5 \% \mathrm{CO}_{2}$ at $37^{\circ} \mathrm{C}$. When the $\mathrm{BFF}$ were at $90 \%$ confluence, they were trypsinized, rinsed, and recultivated in several new $60-\mathrm{mm}$ Petri dishes with fresh culture medium for further passaging.

Human HEK293T cells were used for the luciferase reporter assay, and stored at the Key Laboratory of Animal Biotechnology, Ministry of Agriculture, Northwest A\&F University, and cultured in Dulbecco's modified Eagle's high-glucose medium containing 10\% FBS, in saturation humidity with $5 \% \mathrm{CO}_{2}$ at $37^{\circ} \mathrm{C}$.

\section{Vector Construction}

The DNA fragments corresponding to the miR-101-2 precursor sequence were amplified by PCR from genomic DNA of BFF and cloned into the BamHI and EcoRI restriction sites of pCDH-Promoter-MCS-EF1 Lentivector (CD513B-1, SBI, Mountain View, CA), resulting in the generation of the vector pCDH-miR101. The plasmids Psi-ING3-3'-UTR-wild type (WT) and Psi-ING3-3'-UTR-mutant (Mut) were generated by inserting ING3-3'-UTR-WT or ING3-3'-UTR-Mut into the Psi-check-2 XhoI and NotI restriction sites, respectively. All constructed plasmids were verified by DNA sequencing. Primer sequences are listed in Supplemental Table S1 (https://doi.org/10.3168/jds.2018-15072), and the sequences of the insert fragments are listed in Supplemental Table S2 (https://doi.org/10.3168/jds .2018-15072). 


\section{Cell Transfection and Clone Selection}

Upon reaching $80 \%$ confluence on $60-\mathrm{mm}$ Petri dishes, cells were resuspended in transfer buffer, placed in a 4-mm cuvette gap with $6 \mu \mathrm{g}$ of pCDH-miR101 or pCDH-513-B9 (empty vector), and then electroporated at $510 \mathrm{~V}$ with 3 pulses of 2-ms duration using a BTX Electro Cell Manipulator ECM2001 (BTX, Holliston, MA). The cells were placed in 90-mm Petri dishes to which fresh cell culture medium was added in advance at an average of $5 \times 10^{5}$ cells. After $24 \mathrm{~h}$, the medium containing $2 \mu \mathrm{g} / \mathrm{mL}$ of Puro (Sigma Aldrich) was replaced by a medium containing $1 \mu \mathrm{g} / \mathrm{mL}$ of Puro when floating cells constituted approximately $50 \%$ of the total. Approximately $7 \mathrm{~d}$ later, Puro-resistant clone cells began to emerge and exhibited green fluorescence under UV light. When the clone cells became large enough for transfer, they were moved into new $60-\mathrm{mm}$ Petri dishes and cultured in $500 \mathrm{ng} / \mathrm{mL}$ of Puro. Cells were passaged in several new $60-\mathrm{mm}$ Petri dishes or frozen in 10\% dimethylsulfoxide and 90\% FBS upon reaching $90 \%$ confluence.

\section{Luciferase Reporter Assay}

For the luciferase reporter assay, $5 \times 10^{4} 293 \mathrm{~T}$ cells were plated in each well of a 24 -well plate. The cells were co-transfected with $400 \mathrm{ng}$ of pCDH-miR-101-2 or pCDH-513B and $40 \mathrm{ng}$ of Psi-ING3-3'-UTR-WT or Psi-ING3-3'-UTR-Mut. Using Lipofectamine 2000 (Invitrogen) in accordance with the manufacturer's instructions, cells were collected $48 \mathrm{~h}$ after transfection and analyzed using the Dual-Luciferase Reporter Assay System (TransGen Biotech, Beijing, China). Relative luciferase activity was normalized to Renilla luciferase activity. Transfections were performed in duplicate and repeated at least thrice in independent experiments.

\section{Western Blot Analysis}

Western blot was carried out as previously described with minor modifications (Wang et al., 2018). The cells were collected and washed with PBS, and then lysed using radioimmunoprecipitation assay (RIPA) buffer (Beyotime Inst. Biotech, Beijing, China) with $1 \%$ PMSF and protease inhibitor on ice for $30 \mathrm{~min}$. A bicinchoninic acid protein assay kit (TransGen Biotech) was used for protein quantification. Proteins were separated by $10 \%$ SDS PAGE and transferred to polyvinylidene difluoride membranes (Millipore, Bedford, MA). Membranes were then blocked in 10\% nonfat milk (wt/vol in TBST) for $4 \mathrm{~h}$ and incubated with primary antibodies anti-ING3 (1:1,000, ab84645;
Abcam, Cambridge, UK) and internal reference anti- $\beta$ actin $\left(1: 1,000\right.$, ab8227; Abcam) overnight at $4^{\circ} \mathrm{C}$. After washing 3 times in TBST, membranes were incubated with the secondary antibodies goat anti-rabbit (Beyotime Inst. Biotech, Beijing, China) for $2 \mathrm{~h}$, which followed by washes for 3 times in TBST. After using the chemiluminescence reagent (Beyotime Inst. Biotech), immunoreactive proteins were visualized by autography using SuperSignal West Pico Substrate (Thermo Fisher Scientific, Waltham, MA). All steps were performed at room temperature unless stated otherwise. The gray level of the image was analyzed using Image J (https:/ /imagej.nih.gov/ij/) software.

\section{RNA Extraction, Reverse-Transcription PCR, and Quantitative Real-Time PCR}

For measurement of the expression of mRNA in $\mathrm{BFF}$, total RNA was extracted using Trizol reagent (TransGen Biotech) according to the manufacturer's instructions. First-strand cDNA were prepared from 1 $\mu \mathrm{g}$ of RNA using a reverse transcription kit (TransGen Biotech). The miRNA samples were isolated using the mir-Vana miRNA Isolation Kit and reverse-transcribed using the miScript II RT Kit (Qiagen, Hilden, Germany).

For measurement of the expression of mRNA in embryos, a Cells-to-Signal kit (Ambion Co., Austin, TX) was used to isolate total RNA from IVF and SCNT embryos ( $\mathrm{n}=18$ embryos per pool) according to the manufacturer's instructions. The M-MLV RT reagent included in the kit was used for reverse transcription. Samples of miRNA ( $\mathrm{n}=55$ embryos per pool) were isolated using the miScript Single Cell qPCR Kit (Qiagen) and reverse transcribed using a miScript II RT Kit (Qiagen).

The expression levels of mRNA were measured using SYBR Premix Ex Taq (TaKaRa, Dalian, China) according to the manufacturer's instructions. The GAPDH was selected by GeNorm and NormFinder software as housekeeping gene to normalize mRNA expression levels (Supplemental Tables S3 and S4; https: //doi.org/10.3168/jds.2018-15072; Perez et al., 2007). Mature miRNA expression was quantified using a miScript SYBR Green PCR Kit containing $10 \times$ miScript Universal Primer (Qiagen), according to the manufacturer's instructions. U6 was used as an internal control to normalize miRNA expression levels. The results were expressed as fold change $=2^{-\Delta \Delta \mathrm{Ct}}$. ABI StepOnePlus PCR system (Applied Biosystems, Foster City, CA) was used to perform quantitative real-time PCR (qRTPCR). The PCR cycle conditions were as follows: $95^{\circ} \mathrm{C}$ for $30 \mathrm{~s}$ followed by 40 cycles of $95^{\circ} \mathrm{C}$ for $5 \mathrm{~s}$ and $60^{\circ} \mathrm{C}$ 
for 30 s. Primer sequences were designed to span an intron splice site, and are summarized in Supplemental Table S5 (https://doi.org/10.3168/jds.2018-15072).

\section{Cell Cycle and Apoptosis Analyses}

The progression of the cell cycle and apoptosis were assessed by flow cytometry (Becton Dickinson, Oxford, UK). For analyzing the cell cycle, miR-101-2 and vector clone cells in a $60-\mathrm{mm}$ dish were collected and rinsed with cold PBS and then fixed in $75 \%$ ethanol overnight at $4^{\circ} \mathrm{C}$. Fixed cells were then washed and resuspended in 200 to $500 \mu \mathrm{L}$ of cold PBS supplemented with 20 $\mu \mathrm{L}$ of RNase A and then incubated at $37^{\circ} \mathrm{C}$ for $30 \mathrm{~min}$. This was followed by supplementation of $400 \mathrm{~mL}$ of propidium iodide $(100 \mathrm{mg} / \mathrm{mL})$ staining solution into the resultant cell suspension and then incubated for 0.5 to $1 \mathrm{~h}$ at $4^{\circ} \mathrm{C}$. Results were analyzed by flow cytometry. For analyzing cell apoptosis, miR-101-2 or vector clone cells were collected and washed twice with cold PBS. Then, they were supplemented with $400 \mathrm{~mL}$ of 1_Annexin V (BB-4101, BestBio, Shanghai, China) and 5 $\mathrm{mL}$ of Annexin V-EGFP staining medium (BB-4101, BestBio). This cell suspension was mixed slightly and incubated in the dark for 15 min at 2 to $8^{\circ} \mathrm{C}$. This mixture was then supplemented with $10 \mathrm{~mL}$ of propidium iodide $(10 \mathrm{mg} / \mathrm{mL})$ for $5 \mathrm{~min}$ before flow cytometry.

\section{Cell Proliferation Analysis}

Cell proliferation was measured using the Cell Counting Kit-8 (CCK-8; Beyotime Inst. Biotech) according to the manufacturer's instructions. Briefly, the miR-101-2 clone cells, 513-B1 clone cells, and ordinary fibroblasts were seeded in 96-well plates, with each type of cell having the same density of 2,000 cells per well, being grown at $37^{\circ} \mathrm{C}$ for $24 \mathrm{~h}$. The medium in each well was replaced with a new medium, which was then incubated with $10 \mu \mathrm{L}$ of CCK- 8 for $2 \mathrm{~h}$ at $37^{\circ} \mathrm{C}$. For each group, there were 3 replicates, along with the use of the medium at the same amount as in CCK- 8 as a control. Finally, the absorbance was determined at 450 $\mathrm{nm}$ using a microplate reader.

\section{Oocyte Collection, In Vitro Maturation, NT, and In Vitro Reconstituted Embryo Culture}

Oocyte collection, in vitro maturation, and NT were performed as previously described with minor modifications (Wang et al., 2011). Briefly, slaughterhousederived ovaries were stored in sterile saline at 20 to $25^{\circ} \mathrm{C}$, and transported to the laboratory within $6 \mathrm{~h}$. Cumulus-oocyte complexes (COC) were aspirated from antral follicles (diameter, $2-8 \mathrm{~mm}$ ) with a $10-\mathrm{mL}$ syringe, and only those with multilayered compact cumulus, uniformly dark, and evenly granulated cytoplasm were selected. These oocytes were rinsed thrice in PBS containing 3\% FBS, and cultured for $20 \mathrm{~h}$ in bicarbonate-buffered tissue culture medium 199 (TCM199, Gibco, BRL, Grand Island, NY) supplemented with $10 \%$ FBS, $1 \mathrm{mg} / \mathrm{mL}$ of $17 \beta$-estradiol, and 0.075 $\mathrm{IU} / \mathrm{mL}$ of human menopausal gonadotropin in saturation humidity with $5 \% \mathrm{CO}_{2}$ at $38.5^{\circ} \mathrm{C}$.

The COC were then transferred into PBS with $0.1 \%$ bovine testicular hyaluronidase to disperse the cumulus cells from oocytes. Oocytes with uniform, granulated ooplasm and an extruded first polar body were selected for SCNT. Enucleation was carried out by using a 20$\mu \mathrm{m}$ (internal diameter) glass pipette. The first polar body and a small amount of surrounding cytoplasm were aspirated by the glass pipette in microdrops of PBS supplemented with $7.5 \mu \mathrm{g} / \mathrm{mL}$ of cytochalasin B and 10\% FBS. A single donor cell was then injected into the space between the zona pellucida and oocyte membrane. The oocyte-donor cell complex was transferred into a microdrop of Zimmermann's fusion medium, and sandwiched between 2 platinum electrodes, connected to the micromanipulator. Cell-oocyte fusion was performed by using a double electrical pulse of 35 $\mathrm{V}$ for $10 \mu \mathrm{s}$. Reconstructed embryos were then cultured in modified synthetic oviductal fluid (mSOF) for $2 \mathrm{~h}$, and activated in $5 \mu \mathrm{M}$ ionomycin for $4 \mathrm{~min}$, followed by a 4 -h exposure to $1.9 \mathrm{mM}$ dimethylaminopyridine in mSOF. After activation, the activated embryos were transferred into drops of mSOF medium with $8 \mathrm{mg} /$ $\mathrm{mL}$ of BSA and cultured in a humid atmosphere of $5 \% \mathrm{CO}^{2}$ at $38.5^{\circ} \mathrm{C} .513-\mathrm{B} 1-\mathrm{BFF}$ and miR-101-BFF cells from passage $3-5$ were used as donor cells for SCNT. Serum deprivation was used to induce the $G_{0} / G_{1}$ phase. Embryos were cultured for $8 \mathrm{~d}$ to evaluate their developmental rate.

\section{In Vitro Fertilization}

In vitro fertilization was carried out according to previous descriptions with minor modifications (Zhang et al., 2017). Briefly, frozen-thawed spermatozoa were rinsed and washed in BO-IVF medium (IVF Bioscience, Falmouth, UK) for $30 \mathrm{~min}$. Then, 20 to $25 \mathrm{COC}$ were transferred into a $60-\mu \mathrm{L}$ microdrop of BO-IVF medium (IVF Bioscience) covered by mineral oil, after which $50 \mu \mathrm{L}$ of sperm suspension $\left(2 \times 10^{6}\right.$ spermato$\mathrm{zoa} / \mathrm{mL}$ ) was added into it. After incubating in a humid atmosphere of $5 \% \mathrm{CO}_{2}$ at $38.5^{\circ} \mathrm{C}$ for $18 \mathrm{~h}$, they were transferred and washed in PBS with $0.1 \%$ bovine testicular hyaluronidase to remove cumulus cells and redundant spermatozoa from the zygotes, and then the 
zygotes were transferred to be cultured in $\mathrm{mSOF}$ with $8 \mathrm{mg} / \mathrm{mL}$ of BSA for further use.

\section{Apoptosis Assay}

An apoptosis assay was carried out using the DeadEnd Fluorometric TUNEL (Promega, Madison, WI) system as previously described with minor modifications (Chen et al., 2015). All steps were performed at room temperature, unless stated otherwise. After $7 \mathrm{~d}$ of culture, IVF blastocysts and in vitro cloned blastocysts from the miR-101-BFF nuclear transfer (miR-101-NT) group and the 513-B1-BFF nuclear transfer (513-B1NT) group were cleaned for 5 min in PBS containing $0.2 \%$ polyvinyl acetate (PVA-PBS) and fixed for 2 $\mathrm{h}$ with $4 \%$ paraformaldehyde. After washes in PVAPBS, fixed embryos were permeated by $0.2 \%$ Triton X-100 for $20 \mathrm{~min}$, and transferred into E-buffer for 8 min. All the following procedures were carried out in the dark to prevent fluorescence bleaching. Embryos were incubated for $1 \mathrm{~h}$ at $37^{\circ} \mathrm{C}$ in $51 \mathrm{~mL}$ of apoptosis staining medium ( $45 \mathrm{~mL}$ of E-buffer, $1 \mathrm{~mL}$ of terminal deoxynucleotidyl transferase enzyme, and $5 \mathrm{~mL}$ of nucleotide mix), which was followed by terminating with $2 \times$ saline sodium citrate for 15 min. Embryos were washed again and incubated for $5 \mathrm{~min}$ in 4,6-diamidino2-phenylindole (DAPI; $5 \mathrm{mg} / \mathrm{mL}, \mathrm{C} 1002$, Beyotime, Jiangsu, China). Stained embryos were mounted on a glass slide for observation under a Nikon (Tokyo, Japan) fluorescence microscope. Blastocyst cell numbers were estimated by counting the total number of nuclei using DAPI, and the number of apoptotic cells per blastocyst was determined by counting nuclei positive for green fluorescence.

\section{CDX2 Staining in Blastocysts}

The DAPI staining was performed to reveal the total cell number in blastocysts. The CDX2 staining was used to analyze trophectoderm (TE) cell number. Then, the inner cell mass (ICM) cell number was assessed by calculating the difference between the total cell number and TE cell number.

Blastocysts were collected and washed 3 times ( 5 min each) in PVA-PBS, after which they were fixed with $4 \%$ paraformaldehyde for $2 \mathrm{~h}$ at room temperature. Immunol Staining Blocking Solution (P0102, Beyotime, Jiangsu, China) was used to block blastocysts for 12 $\mathrm{h}$ at $4^{\circ} \mathrm{C}$ before washing them 3 times ( 5 min each) in PVA-PBS. Then, blastocysts were washed 3 times (5 min each) in PVA-PBS, which was followed by incubating them for $12 \mathrm{~h}$ at $4^{\circ} \mathrm{C}$ with anti-CDX2 mouse monoclonal antibody (BioGenex Inc., San Ramon, CA) diluted 1:300 in Immunol Staining Primary Antibody
Dilution Solution (P0103, Beyotime). After 3 cleanings, samples were incubated for $2 \mathrm{~h}$ at room temperature with Alexa Fluor 555-labeled goat anti-mouse IgG secondary antibody (A0459, Beyotime) diluted 1:600 in Immunol Staining Secondary Antibody Dilution Solution (P0108, Beyotime). Then we performed another 3 washes and used $5 \mathrm{mg} / \mathrm{mL}$ of DAPI (C1002, Beyotime) to stain the nucleus for 5 min. Samples were then cleaned and mounted on a glass slide with a drop of Antifade Mounting Medium (P0126, Beyotime) for analysis using a Nikon fluorescence microscope. The cell numbers in blastocysts were estimated by counting nuclei stained with DAPI, and the number of TE cells was determined by counting nuclei positive for CDX2. The cell number of ICM was estimated as the total number of nuclei minus the number of TE nuclei.

\section{Statistical Analysis}

Statistical analysis was performed using GraphPad Prism 6.0 software (GraphPad Software Inc., San Diego, CA). Data are presented as the mean \pm standard deviation or mean \pm standard error of the mean from at least 3 independent experiments. All embryos had been systematically produced from the same cohort of oocytes on the same day and were allocated randomly to each treatment group. The development rate, apoptosis rate, ICM/TE ratio, and total cell number were analyzed using one-way ANOVA. The relative gene expressions were established by testing the data for normal and equal variance using the Levene median test, ANOVA, followed by the Tukey's test for multiple pairwise comparisons. The 2-tailed Student's t-test was used for pairwise comparisons of relative luciferase activity. $P$-values $<0.05$ were considered statistically significant.

\section{RESULTS AND DISCUSSION}

\section{ING3 Is a Direct Target of miR-101-2}

Our analysis reveals that ING3, a member of the inhibitor of growth family, was a potential target of miR-101-2, as the 3 '-UTR in ING3 mRNA contained a complementary site for the seed region of miR-1012 (Figure 1A). To confirm that ING3 is a target of miR-101-2, we co-transfected the reporter plasmid psiCHECK2-ING3-3'-UTR WT or Mut and the miR101-2 expression plasmid PCDH-miR-101-2 into the HEK293T cell line. As predicted, the relative luciferase activity of the WT 3'-UTR reporter significantly decreased in cells co-transfected with pCDH-miR-101-2 compared with that in cells co-transfected with empty $\mathrm{PCDH}$ vector. In contrast, the luciferase activity upon 
the co-transfection of mutant 3'-UTR reporter and pCDH-miR-101-2 was no longer able to be suppressed compared with that in cells co-transfected with empty PCDH vector. These results indicate that miR-101-2 targets the 3 '-UTR of ING3, directly suppressing its gene expression (Figure 1B). To test the hypothesis that miR-101-2 could downregulate ING3 protein expression in bovine fibroblasts, we first obtained the clone cells with pCDH-miR-101-2 or PCDH vector. We found that the overexpression of miR-101-2 caused significant decreases in ING3 at both protein and mRNA levels (Figures $1 \mathrm{C}$ and 2). These findings indicate that the presence of miR-101-2 in bovine fibroblasts suppresses ING3 expression.

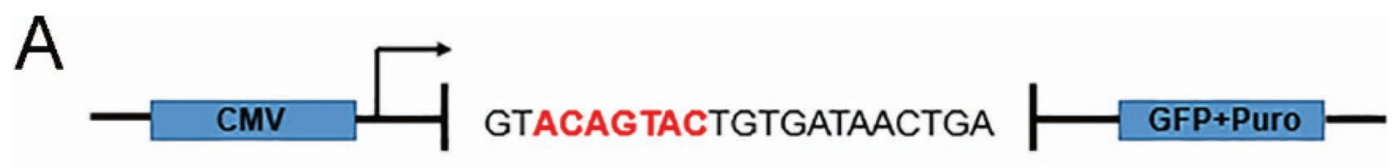

B
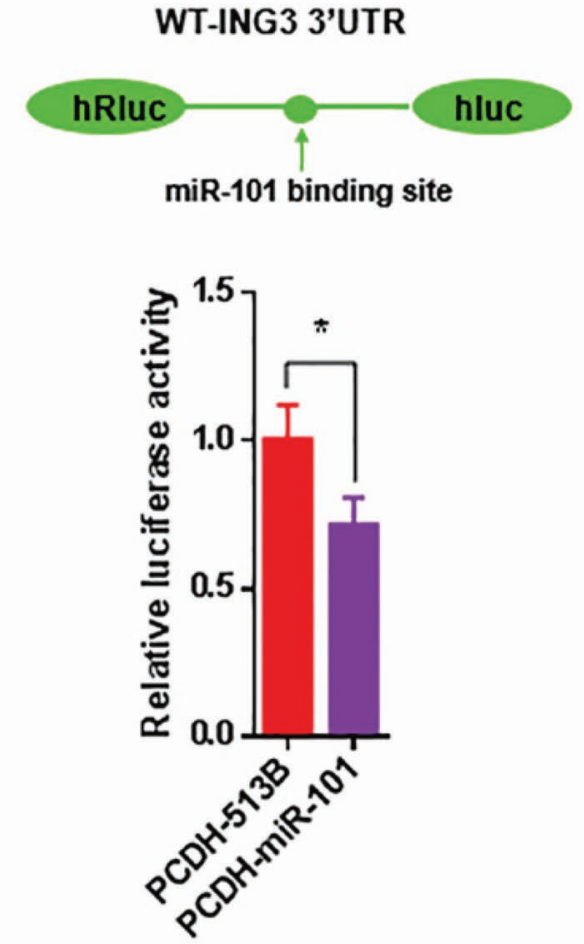

MUT-ING3 3'UTR
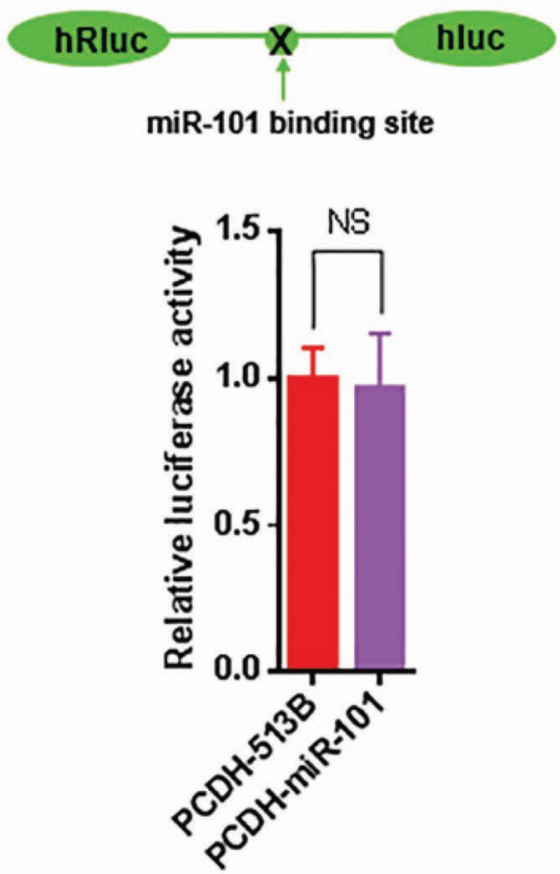

C

\section{Vector miR-101}

\section{ING3}

$\beta$-actin

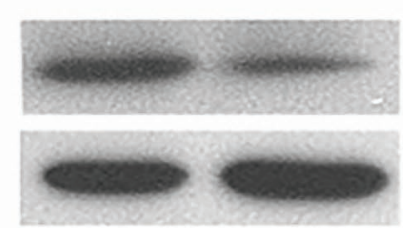

Figure 1. The ING3 gene is direct target of miR-101-2. (A) The part structure of miR-101-2 overexpression vector PCDH-miR-101-2 . (B) Dual-luciferase assay of $293 \mathrm{~T}$ cells co-transfected with the firefly luciferase constructs containing the ING3 wild type (WT) or mutant (MUT) 3'-untranslated region (UTR) as well as miR-101-2 overexpression vector PCDH-miR-101-2 or the empty PCDH-513-B1 as the negative control. (C) Western blot analysis of the protein levels of ING3 in response to miR-101-2 overexpression. $\beta$-actin was used as a loading control. Data are shown as mean $\pm \mathrm{SD}$ from 3 experimental replicates $\left({ }^{*} P<0.05\right)$. 
miR-101-2 Affects the Expression of ING3 and Related Genes in miR-101-BFF

First, we tested whether miR-101-2 was successfully overexpressed after transfection and found that miR101-2 expression was greatly upregulated (about 15fold) in miR-101-BFF compared with that in 513-B1$\mathrm{BFF}$ and $\operatorname{BFF}(P<0.01$; Supplemental Figure S1; https://doi.org/10.3168/jds.2018-15072).

The ING3 activates TP53-transactivated promoters and modulates TP53-mediated transcription and apoptosis. Against this background, we tested a series of apoptosis-related genes to reveal whether these regulators are involved in the apoptosis inhibition of miR-101-2. We checked the mRNA levels of some regulators by qRT-PCR, including ING3, TP53, CDKN1A, $B A X$, and BCL2L1. The results showed that the levels of ING3, TP53, CDKN1A, and BAX decreased significantly in miR-101-BFF $(P<0.05)$ compared with that in 513-B1-BFF, whereas BCL2L1 level showed an increase in miR-101-BFF $(P<0.05)$ compared with that in 513-B1-BFF (Figure 2). These findings indicate that miR-101-2 can affect the expression of some apoptosisrelated genes.

\section{Effects of miR-101-2 Overexpression on Apoptosis, Cell Cycle, and Proliferation}

The nuclear donor cell is a crucial factor affecting SCNT embryo quality and the efficiency of SCNT, and many efforts have been made to improve them by improving donor-cell status (Chen et al., 2015; Mizutani

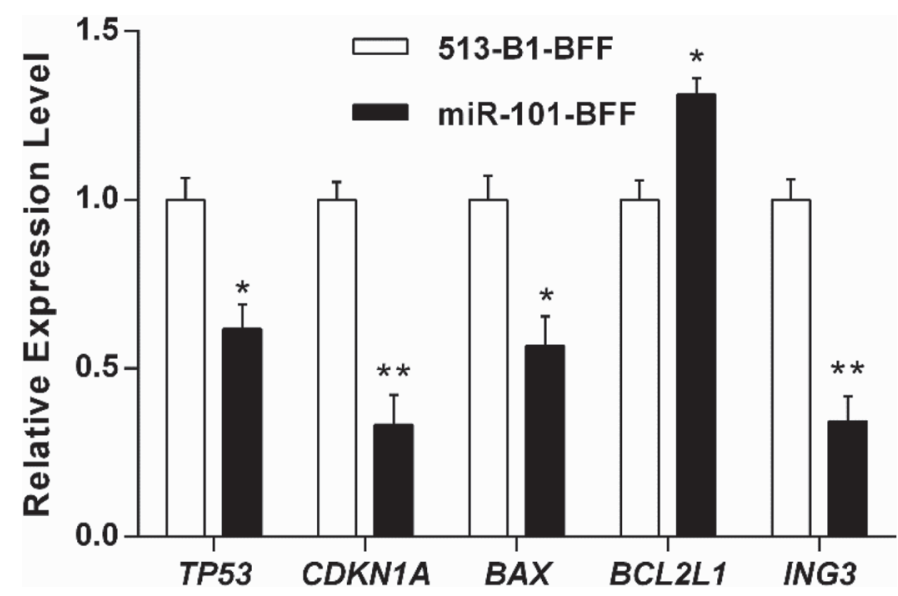

Figure 2. The mRNA expression of ING3 and apoptosis-related genes in 513-B1-bovine fetal fibroblasts (BFF) and miR-101-BFF. ING3, TP53, CDKN1A, BAX, and BCL2L1 mRNA expression was assessed by real-time PCR in 513-B1-BFF (BFF transfected with empty vectors) and miR-101-BFF (BFF with miR-101-2 overexpression). Data are shown as mean \pm SEM from 3 experimental replicates $\left({ }^{*} P\right.$ $\left.<0.05,{ }^{*} * P<0.01\right)$. et al., 2015). Furthermore, miR-101 can regulate cell proliferation, the cell cycle, and apoptosis in different cell types (Wang et al., 2014b; Zhou et al., 2015; Qian et al., 2016). Therefore, we detected the apoptosis, cell cycle, and proliferation in donor cells after miR-101-2 overexpression.

The clone cells miR-101-BFF and 513-B1-BFF were first examined by flow cytometry to test whether miR101-2 could affect apoptosis and cell cycle distribution of BFF. The miR-101-BFF had lower percentages of apoptotic and dead cells than in 513-B1-BFF (Figure $3 \mathrm{~A}$ ). These findings indicate that miR-101-2 could inhibit apoptosis in BFF.

Recently, many studies have focused on the association of miR-101 with apoptosis and cell proliferation through interaction with its target genes. The miR-101 inhibits the apoptosis of trophoblast HTR-8/SVneo cells by targeting endoplasmic reticulum protein 44 during preeclampsia (Zou et al., 2014). By contrast, the overexpression of human ING3, a putative homolog of the Caenorhabditis elegans ING3 gene, promotes apoptosis (Nagashima et al., 2003; Wang et al., 2007). In the present study, we found that miR-101-2 downregulated ING3 and inhibited the apoptosis of bovine SCNT donor cells. The miR-101-2 was inversely correlated with ING3 in apoptosis regulation. It has also been suggested that ING3 overexpression increases the apoptotic rate of RKO cells (WT TP53) but not RKO-E6 cells (inactivated TP53), and it was further confirmed that ING3 activates TP53-transactivated promoters, including the promoters of CDKN1A and $B A X$ (Nagashima et al., 2003; Jafarnejad and Li, 2012). The ING3-mediated apoptosis occurs in a TP53dependent/independent manner or via the inhibition of CASP8 or FAS activation (Garkavtsev et al., 1998; Wang et al., 2007; Coles and Jones, 2009). In our study, the mRNA levels of TP53, CDKN1A, and BAX were decreased significantly following miR-101-2 overexpression. Accordingly, we infer that miR-101-2 regulation of apoptosis by targeting ING3 in BFF may occur in a TP53-dependent manner.

The flow cytometry results demonstrated that the percentage of cells in the $G_{1}$ phase decreased and the percentage of cells in the $\mathrm{S}$ phase increased in the clone cells miR-101-BFF compared with that in the clone cells 513-B1-BFF. This indicates that miR-101-2 may be involved in the $\mathrm{G}_{1}$-to-S phase transition. These findings show that the $\mathrm{G}_{1}$-to-S phase transition of BFF can be expedited by miR-101-2 (Figure 3B). To investigate the possible function of miR-101-2 in BFF, we examined its effect on cell proliferation. The CCK8 assay results showed that the overexpression of miR-101-2 resulted in the promotion of the growth of BFF compared with that of the vector control (Figure $3 \mathrm{C}$ ). 
A

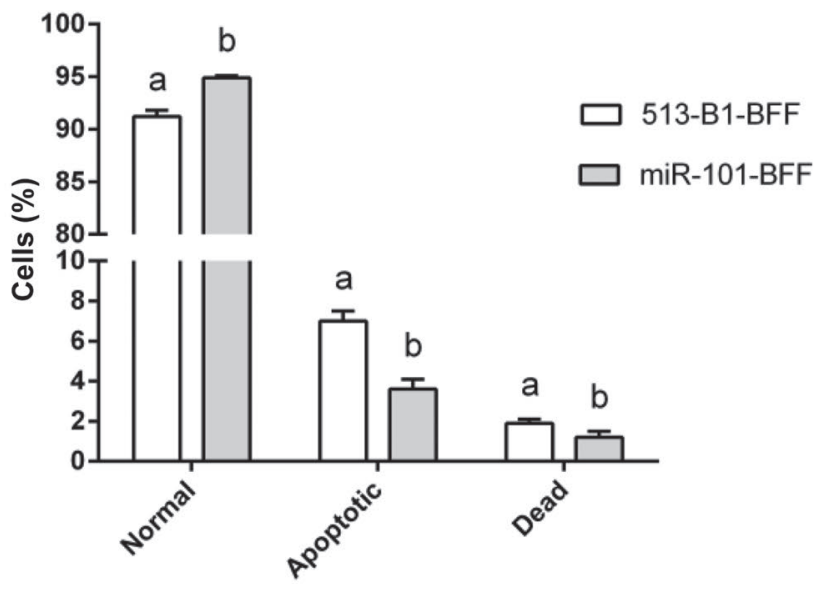

B

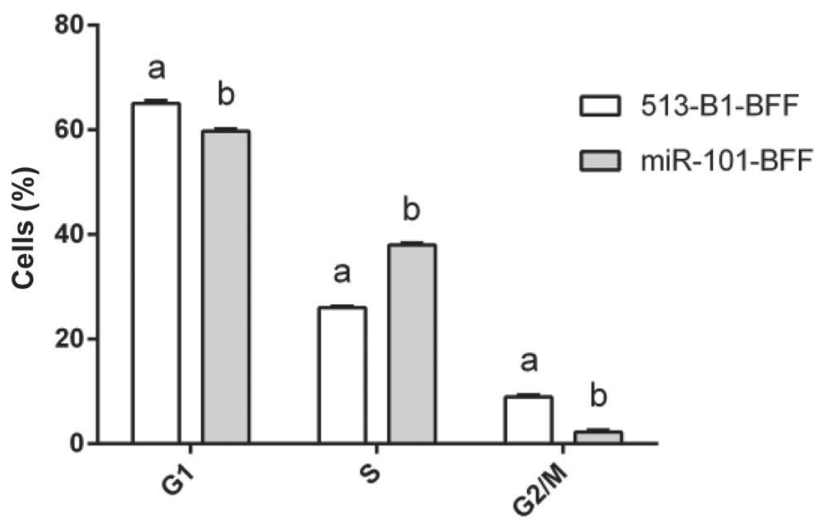

C

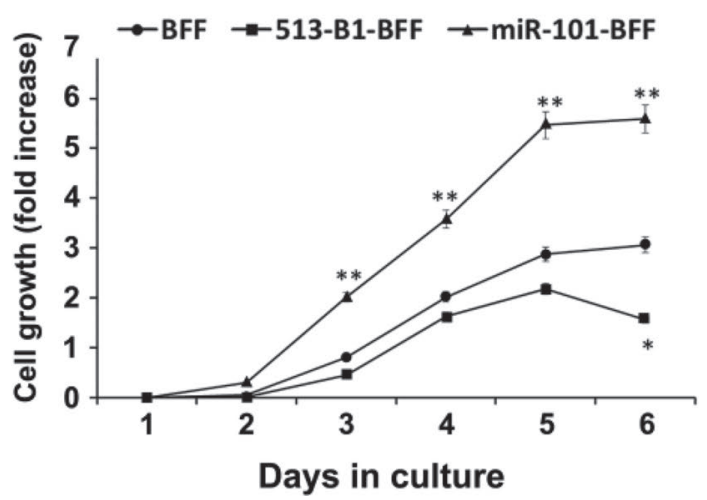

Figure 3. Effect of miR-101-2 overexpression on cell status. (A) Flow cytometry results show the effect of miR-101-2 overexpression on cell status. The $\mathrm{x}$-axis represents cell status. Different letters $(\mathrm{a}, \mathrm{b})$ indicate $P<0.05$. (B) Flow cytometry results show the effect of miR101-2 overexpression on cell-cycle distribution. The $\mathrm{x}$-axis represents the cell cycle stage. $\mathrm{G}_{1}=$ first gap; $\mathrm{S}=$ synthesis; $\mathrm{G}_{2} / \mathrm{M}=$ second gap $/$ mitotic phase. Different letters $(\mathrm{a}, \mathrm{b})$ indicate $P<0.05$. (C) CCK8 assays were performed to investigate the effect of miR-101-2 on the proliferation of bovine fetal fibroblasts (BFF) at the indicated time points. Data are shown as mean \pm SEM from 3 experimental replicates $\left({ }^{*} P<0.05,{ }^{* *} P<0.01\right)$.
The miR-101 could inhibit cell proliferation by targeting certain genes ( $R A C 1, F O S, M I T F$, and SOCS2; Konno et al., 2014; Wang et al., 2014a; Zheng et al., 2015). However, we found that miR-101-2 promoted the proliferation of bovine SCNT donor cells, which is probably because it downregulates ING3. ING3 is one member of the well-conserved family of ING proteins, and the overexpression of ING3 in RKO cells resulted in a decreased proportion of cells in $\mathrm{S}$ phase and an increased proportion in $G_{0} / G_{1}$ phase, suppressing cell growth (Nagashima et al., 2003). We found that the downregulation of ING3 via miR-101-2 overexpression resulted in a decreased proportion of cells in $G_{1}$ phase and an increase in proportion in $\mathrm{S}$ phase in BFF. These findings showed that miR-101-2 could accelerate the proliferation of $\mathrm{BFF}$.

\section{Characterization of miR-101-2 Expression in IVF and SCNT Embryos}

The qRT-PCR results showed that the expression of miR-101-2 in 513-B1-NT group was lower than that in IVF group at the 2 -cell and 8-cell stage $(P<0.05$; Figure 4), whereas it reached a similar level in the IVF group when using miR-101-BFF as donor cells $(P>0.05)$. However, miR-101-2 expression levels at the blastocyst stage showed no significant differences $(P>0.05)$. Wang et al. (2017b) indicated using donor cells with miR-148a overexpression could upregulate its expression in cloned embryo, and similar results were found in another study, with miR-449b being selected (Wang et al., 2017a). These results are in line with our findings.

\section{Effects of miR-101-2 Overexpression on the Quality of Cloned Blastocysts}

Primarily, we analyzed the differences in developmental rate among 3 groups. The 2 -cell rate and 8 -cell rate between the miR-101-BFF NT (miR-101-NT) group and the 513-B1-BFF NT (513-B1-NT) group showed no significant difference $(78.42 \pm 2.07$ vs. $75.76 \pm 0.61$ and $51.66 \pm 1.98$ vs. $47.80 \pm 1.28$, respectively, $P>$ $0.05)$, which were both lower than that of IVF embryos $(P<0.05)$. The blastocyst rate has been widely used as an index of blastocyst quality in studies on SCNT (Liu et al., 2018). Day-7 blastocyst rate, however, was higher in the miR-101-NT group than in the 513-B1NT group $(39.08 \pm 1.08$ vs. $32.90 \pm 2.10, P<0.05)$, attaining a rate comparable to that of IVF embryos, and Day- 8 blastocyst rate showed similar tendency in miR-101-NT, 513-B1-NT, and IVF group $(44.68 \pm 1.35$ vs. $37.93 \pm 1.97$ vs. $47.01 \pm 1.43$, Table 1 ). 


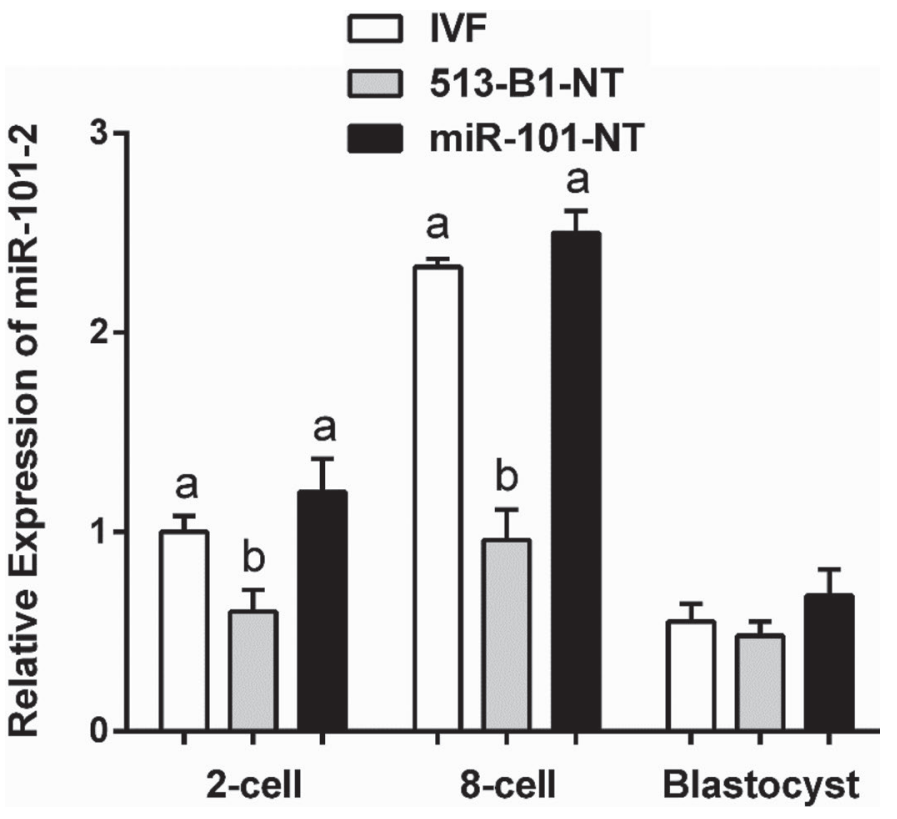

Figure 4. The expression pattern of miR-101-2 in in vitro fertilized (IVF) and somatic cell nuclear transfer (SCNT) embryos. Relative miR-101-2 expression level of genes in 2-cell, 8-cell, and d-7 blastocysts from IVF, 513-B1-NT [SCNT embryos produced by using bovine fetal fibroblasts $(\mathrm{BFF})$ transfected with empty vectors as donor cells], or miR-101-NT groups (SCNT embryos produced by using BFF with miR-101-2 overexpression as donor cells). Different letters (a,b) indicate $P<0.05$. The results from 2 -cell IVF samples are set as 1 . Data are shown as mean \pm SEM from 3 experimental replicates.

We also performed immunostaining of blastocysts for the trophectoderm marker CDX2 and the DNA marker DAPI to compare the numbers of different cell types among the 3 groups (Figures 5A and 5B). Total cell number for individual 513-B1-NT blastocysts was less than that for IVF blastocysts ( 86.4 vs. 102.5, $P<0.05$ ), but this figure rose significantly when miR-101-BFF was used as donor cells (100.8 vs. 86.4, $P<0.05)$. The $\mathrm{ICM} / \mathrm{TE}$ ratio was also significantly higher in the miR101-NT group than in the 513-B1-NT counterpart (28.8 vs. $23.9 \%, P<0.05$ ), at a level comparable to that of the IVF group, whereas ICM cell number between these groups did not show significant difference (Figure 5B).
To clarify why a higher ICM/TE ratio was found in the miR-101-NT group, qRT-PCR was performed to reveal the expression levels of 4 development-related genes, namely, POU5F1 NANOG, SOX2, and CDX2; among these, POU5F1 and SOX2 were upregulated in the miR-101-NT group (Figure 6).

The POU5F1 gene (also known as OCT4), which encodes a factor that maintains ICM fate, plays a key role in embryonic development and stem cell pluripotency. It has been reported that POU5F1 transcript levels were decreased in clones compared with those in IVF embryos at the blastocyst stage (Beyhan et al., 2007). Similar results were obtained in our study. The SOX2 is also involved in maintaining pluripotency. In ICM cells, SOX2 collaborating with POU5F1 and NANOG acts as a circuit to form the pluripotent regulatory network (Chen et al., 2008; Kim et al., 2008). The observed rise in the expression of $S O X 2$ and POU5F1, but not in NANOG or CDX2, in the miR-101-NT group is consistent with previous studies indicating the relationship between the expression of related genes and blastocyst quality (Su et al., 2011; Chen et al., 2015).

Serum starvation treatment is commonly used in SCNT, but it might result in DNA damage and subsequent apoptosis. Therefore, apoptosis was considered as a criterion for the evaluation of blastocyst quality (Hardy, 1997). Here, results indicated the apoptotic rate in 513-B1-NT embryos was significantly higher than that in IVF embryos. The apoptotic rate was lower in miR-101-NT blastocysts than in the 513-B1NT group $(P<0.05)$, at levels comparable to those in IVF embryos (Figures $5 \mathrm{C}$ and $5 \mathrm{D}$ ). Furthermore, the expression of ING3 and several genes associated with apoptosis was assessed by qRT-PCR (Figure 6). The BCL2L1 was upregulated in miR-101-NT blastocysts compared with that in the IVF group and the 513-B1-NT group $(P<0.05)$. The ING3 expression was higher in 513-B1-NT than in the IVF blastocysts $(P$ $<0.01$ ), but it decreased significantly in miR-101-NT blastocysts compared with the 513-B1-NT group $(P<$ 0.01). The expression of $B A X$ was lower in miR-101-NT blastocysts than in both the IVF and the 513-B1-NT group $(P<0.05)$.

Table 1. Effect of micro RNA miR-101-2 on the development of cloned bovine embryos in vitro ${ }^{1}$

\begin{tabular}{lccrrr}
\hline Group $^{2}$ & $\begin{array}{c}\text { No. of } \\
\text { reconstructed }\end{array}$ & $\begin{array}{c}\text { No. of cleaved } \\
\text { embryos (\%) }\end{array}$ & $\begin{array}{c}\text { No. of 8-cell } \\
(\%) \text { per 2-cell }\end{array}$ & $\begin{array}{c}\text { No. of blastocysts on } \\
7 \text { d (\%) per 2-cell }\end{array}$ & $\begin{array}{c}\text { No. of blastocysts on } \\
8 \text { d (\%) per 2-cell }\end{array}$ \\
\hline IVF & 211 & $178(84.38 \pm 1.16)^{\mathrm{a}}$ & $101(56.66 \pm 0.89)^{\mathrm{a}}$ & $77(42.80 \pm 1.78)^{\mathrm{a}}$ & $83(47.01 \pm 1.43)^{\mathrm{a}}$ \\
$513-B 1-N T$ & 165 & $125(75.76 \pm 0.61)^{\mathrm{b}}$ & $60(47.80 \pm 1.28)^{\mathrm{b}}$ & $42(32.90 \pm 2.10)^{\mathrm{b}}$ & $47(37.93 \pm 1.97)^{\mathrm{b}}$ \\
miR-101-NT & 193 & $151(78.42 \pm 2.07)^{\mathrm{b}}$ & $78(51.66 \pm 1.98)^{\mathrm{b}}$ & $60(39.08 \pm 1.08)^{\mathrm{a}}$ & $67(44.68 \pm 1.35)^{\mathrm{a}}$ \\
\hline
\end{tabular}

\footnotetext{
${ }^{\mathrm{a}, \mathrm{b}}$ Values with different superscripts within columns differ significantly $(P<0.05)$.

${ }^{1}$ Three replicates were performed. The data are shown as mean \pm SEM.

${ }^{2} \mathrm{IVF}=$ in vitro fertilization; 513-B1-NT = somatic cell nuclear transfer (SCNT) embryos produced by using bovine fetal fibroblasts (BFF) transfected with empty vectors as donor cells; miR-101-NT = SCNT embryos produced by using BFF with miR-101-2 overexpression as donor cells.
} 
The suppression of ING3 was associated with fewer apoptotic germ cells in C. elegans. Also, the embryonic death rate was decreased in the ING3 mutant (Luo et al., 2009). Here, ING3 expression in SCNT blastocysts was suppressed when using miR-101-BFF as donor cells. The $B C L 2$ family proteins influence programmed cell death or apoptosis, among which BCL2L1 is antiapoptotic, whereas $B A X$ is proapoptotic (Martinou and Youle, 2011). We measured the transcript abundance of $B A X$ and $B C L 2 L 1$ among the 3 groups and found that $B A X$ was downregulated and BCL2L1 was upregulated in the miR-101-NT group compared with their levels in the 513-B1-BFF and IVF counterparts. These results are consistent with previous studies indicating the relationship between the expression of related genes and apoptosis ( $\mathrm{Su}$ et al., 2011). Taking these findings together, the changes of expression of ING3, BAX, and $B C L 2 L 1$ might contribute to the decrease in apoptotic rate in miR-101-NT blastocysts.

Collectively, these results demonstrated that the quality of cloned blastocysts from miR-101-BFF was better than for those derived from 513-B1-BFF, which was similar to the quality of IVF blastocysts. Poor embryo quality has been a major problem contributing to pregnancy failure in SCNT (Choi et al., 2013). Great effort has been placed into enhancing developmental competence of SCNT embryos, and they found that those cloned blastocysts with better quality (lower
A

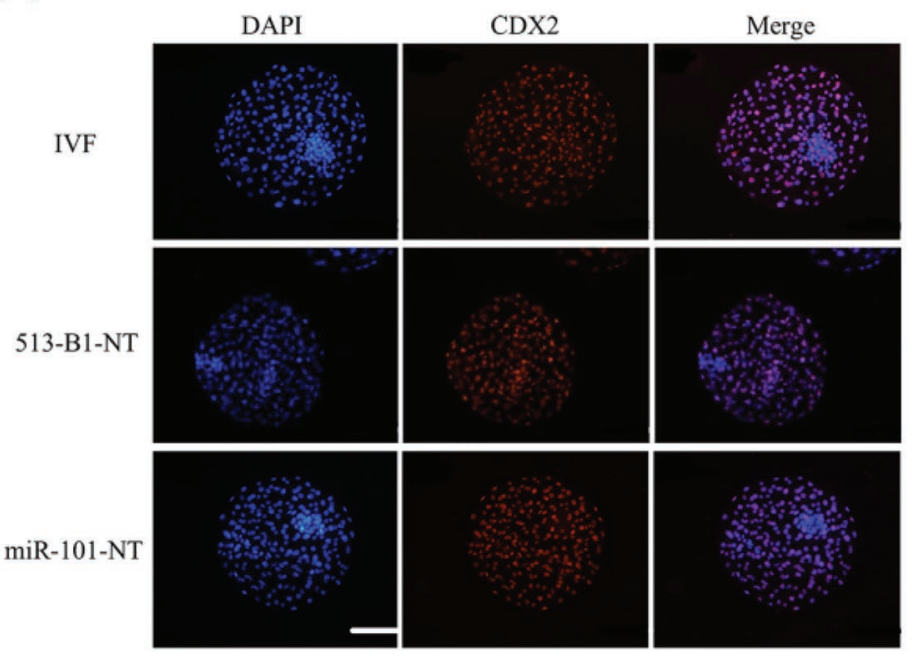

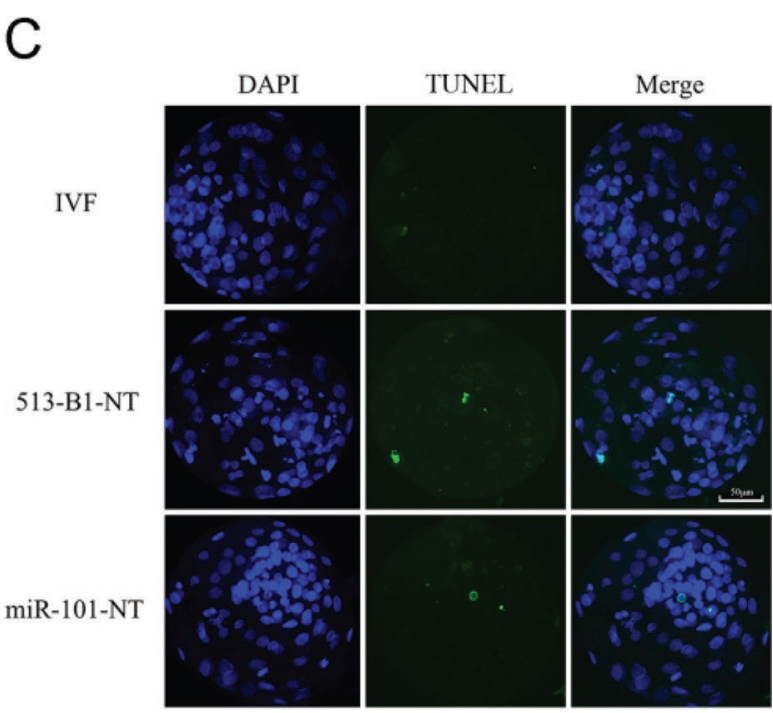

D
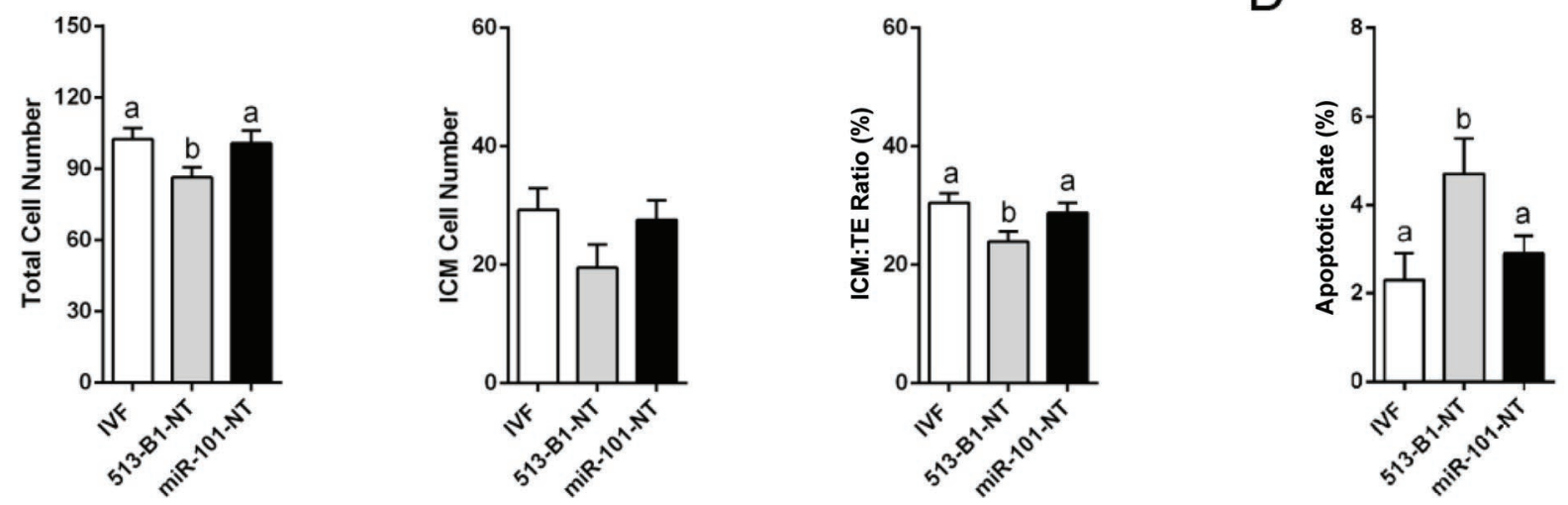

Figure 5. Overexpression miR-101-2 enhance the early development of somatic cell nuclear transfer (SCNT) embryos. (A) Immunostaining of CDX2 (red) and 4,6-diamidino-2-phenylindole (DAPI; blue) in blastocysts from in vitro fertilized (IVF), 513-B1-NT (SCNT embryos produced by using bovine fetal fibroblasts (BFF) transfected with empty vectors as donor cells), and miR-101-NT (SCNT embryos produced by using BFF with miR-101-2 overexpression as donor cells) groups. Scale bar $=50 \mu \mathrm{m}$. (B) Histogram shows the total cell number, inner cell mass (ICM) cell number, and ICM:trophectoderm (TE) ratio of each blastocyst from IVF, 513-B1-NT, and miR-101-NT groups (n = 34, 28, and 31, respectively). Different letters (a,b) indicate $P<0.05$. (C) Apoptotic cells (green) in the nuclei (blue) of blastocysts in IVF, 513-B1-NT, and miR-101-NT. Scale bar $=50 \mu \mathrm{m}$. (D) The apoptotic rate in blastocysts from IVF, 513-B1-NT, and miR-101-NT groups (n = 32, 23, and 28, respectively). Different letters $(\mathrm{a}, \mathrm{b})$ indicate $P<0.05$. Data are shown as mean \pm SEM from 3 experimental replicates. TUNEL $=$ terminal deoxynucleotidyl transferase-mediated dUTP nick-end labeling. 


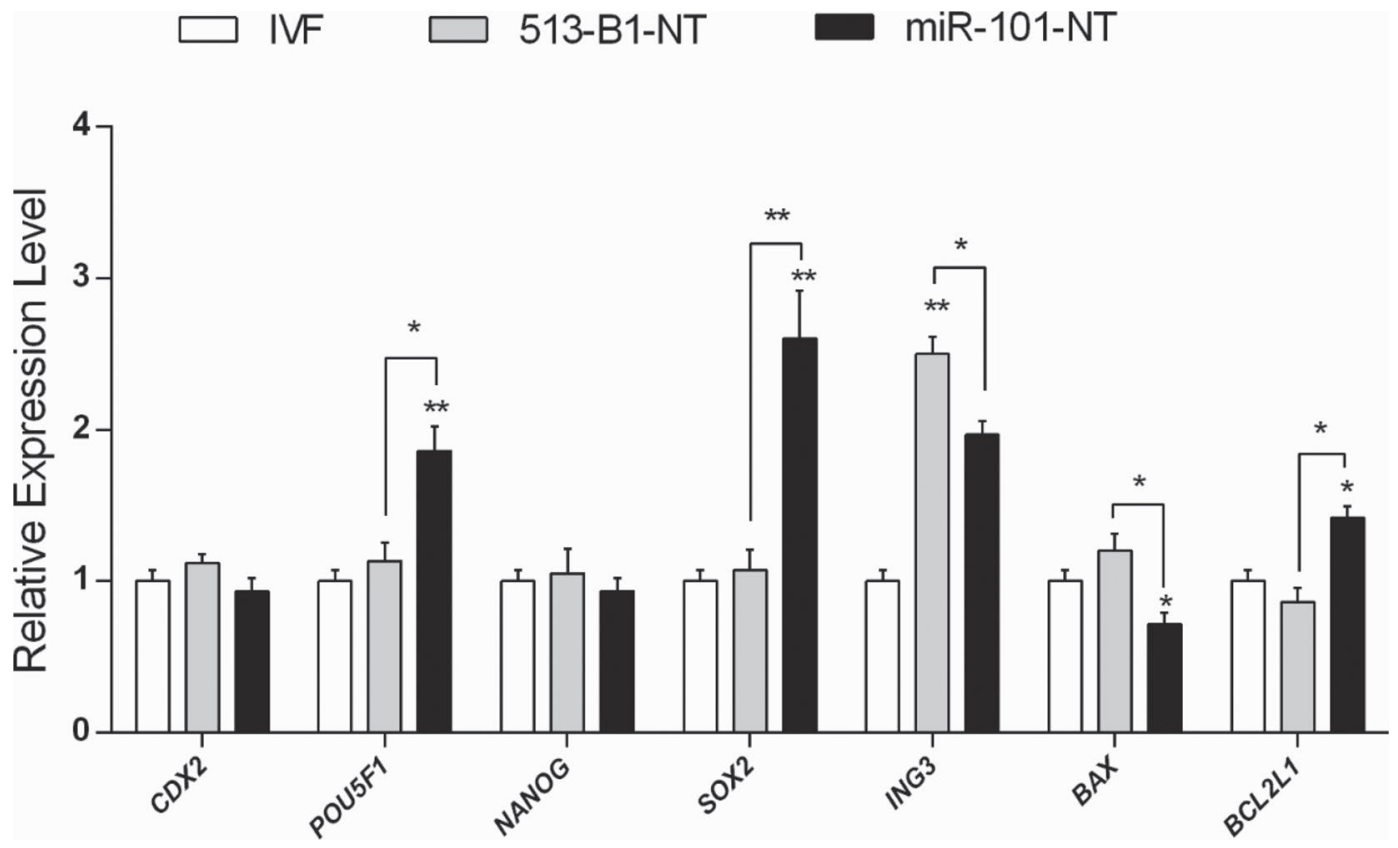

Figure 6. Relative expression of development-related genes and apoptosis-related genes. Relative expression level of genes in d-7 blastocysts from in vitro fertilization (IVF). 513-B1-NT = somatic cell nuclear transfer (SCNT) embryos produced by using bovine fetal fibroblasts (BFF) transfected with empty vectors as donor cells; miR-101-NT = SCNT embryos produced by using BFF with miR-101-2 overexpression as donor cells. Three experimental replicates were performed. Data are shown as mean \pm SEM from 3 experimental replicates $\left(* P<0.05,{ }^{*} P<0.01\right)$.

apoptotic rate, more total cell number, and so on) tend to be more able to result in development in vivo (higher pregnancy rate, birth rate, and so on) after performing embryo transfer (Su et al., 2015; Liu et al., 2018). However, whether miR-101-2 would improve the in vivo development of bovine SCNT embryos needs further investigation.

\section{CONCLUSIONS}

Our results indicate that miR-101-2 can reduce cell apoptosis and expedite the cell cycle. More importantly, it can also enhance the development rate and reduce the apoptotic rate in SCNT embryos and subsequently enhance the early development of bovine SCNT embryos.

\section{ACKNOWLEDGMENTS}

We thank our laboratory colleagues for their help in this study. This work was supported by the National Science and Technology Major Project (no. 2016ZX08007-002; Yangling, China).

\section{REFERENCES}

Agarwal, V., G. W. Bell, J.-W. Nam, and D. P. Bartel. 2015. Predicting effective microRNA target sites in mammalian mRNAs. elife 4:e05005.
Awe, J. P., and J. A. Byrne. 2013. Identifying candidate oocyte reprogramming factors using cross-species global transcriptional analysis. Cell. Reprogram. 15:126-133.

Baguisi, A., E. Behboodi, D. T. Melican, J. S. Pollock, M. M. Destrempes, C. Cammuso, J. L. Williams, S. D. Nims, C. A. Porter, and P. Midura. 1999. Production of goats by somatic cell nuclear transfer. Nat. Biotechnol. 17:456-461.

Beyhan, Z., E. Forsberg, K. Eilertsen, M. Kent-First, and N. First. 2007. Gene expression in bovine nuclear transfer embryos in relation to donor cell efficiency in producing live offspring. Mol. Reprod. Dev. 74:18-27.

Chen, H., L. Zhang, Z. Guo, Y. Wang, R. He, Y. Qin, F. Quan, and Y. Zhang. 2015. Improving the development of early bovine somaticcell nuclear transfer embryos by treating adult donor cells with vitamin C. Mol. Reprod. Dev. 82:867-879.

Chen, X., H. Xu, P. Yuan, F. Fang, M. Huss, V. B. Vega, E. Wong, Y. L. Orlov, W. Zhang, and J. Jiang. 2008. Integration of external signaling pathways with the core transcriptional network in embryonic stem cells. Cell 133:1106-1117.

Choi, I., J. Zhu, and K. H. Campbell. 2013. The combined treatment of calcium ionophore with strontium improves the quality of ovine SCNT embryo development. Zygote 21:139-150.

Coles, A. H., and S. N. Jones. 2009. The ING gene family in the regulation of cell growth and tumorigenesis. J. Cell. Physiol. 218:45-57.

Garkavtsev, I., I. A. Grigorian, V. S. Ossovskaya, and M. V. Chernov. 1998. The candidate tumour suppressor p33ING1 cooperates with p53 in cell growth control. Nature 391:295-298.

Hardy, K. 1997. Cell death in the mammalian blastocyst. Mol. Hum. Reprod. 3:919-925.

Inoue, K., S. Noda, N. Ogonuki, H. Miki, S. Inoue, K. Katayama, K. Mekada, H. Miyoshi, and A. Ogura. 2007. Differential developmental ability of embryos cloned from tissue-specific stem cells. Stem Cells 25:1279-1285.

Jafarnejad, S. M., and G. Li. 2012. Regulation of p53 by ING family members in suppression of tumor initiation and progression. Cancer Metastasis Rev. 31:55-73. 
Kim, J., J. Chu, X. Shen, J. Wang, and S. H. Orkin. 2008. An extended transcriptional network for pluripotency of embryonic stem cells. Cell 132:1049-1061.

Konno, Y., P. Dong, Y. Xiong, F. Suzuki, J. Lu, M. Cai, H. Watari, T. Mitamura, M. Hosaka, and S. J. Hanley. 2014. MicroRNA-101 targets EZH2, MCL-1 and FOS to suppress proliferation, invasion and stem cell-like phenotype of aggressive endometrial cancer cells. Oncotarget 5:6049.

Le, R., Z. Kou, Y. Jiang, M. Li, B. Huang, W. Liu, H. Li, X. Kou, W. He, and K. L. Rudolph. 2014. Enhanced telomere rejuvenation in pluripotent cells reprogrammed via nuclear transfer relative to induced pluripotent stem cells. Cell Stem Cell 14:27-39.

Li, W., Y. Xiong, F. Wang, X. Liu, Y. Gao, Y. Wang, Y. Zhang, and Y. Jin. 2016. MicroRNA-145 inhibitor significantly improves the development of bovine somatic cell nuclear transfer embryos in vitro. Cell. Reprogram. 18:230-236.

Liang, X., Y. Liu, L. Zeng, C. Yu, Z. Hu, Q. Zhou, and Z. Yang. 2014. miR-101 inhibits the G1-to-S phase transition of cervical cancer cells by targeting Fos. Int. J. Gynecol. Cancer 24:1165-1172.

Lin, X., H. Guan, H. Li, L. Liu, J. Liu, G. Wei, Z. Huang, Z. Liao, and Y. Li. 2014. miR-101 inhibits cell proliferation by targeting Rac1 in papillary thyroid carcinoma. Biomed. Rep. 2:122-126.

Liu, X., Y. Wang, Y. Gao, J. Su, J. Zhang, X. Xing, C. Zhou, K. Yao, Q. An, and Y. Zhang. 2018. H3K9 demethylase KDM4E is an epigenetic regulator for bovine embryonic development and a defective factor for nuclear reprogramming. Development 145:dev158261.

Luo, C., P. R. Merz, Y. Chen, E. Dickes, A. Pscherer, D. Schadendorf, and S. B. Eichmüller. 2013. MiR-101 inhibits melanoma cell invasion and proliferation by targeting MITF and EZH2. Cancer Lett. $341: 240-247$

Luo, J., S. Shah, K. Riabowol, and P. E. Mains. 2009. The Caenorhabditis elegans ing-3 gene regulates ionizing radiation-induced germcell apoptosis in a p53-associated pathway. Genetics 181:473-482.

Martinou, J.-C., and R. J. Youle. 2011. Mitochondria in apoptosis: Bcl-2 family members and mitochondrial dynamics. Dev. Cell 21:92-101.

Mizutani, E., S. Wakayama, and T. Wakayama. 2015. Treatment of donor cell/embryo with different approaches to improve development after nuclear transfer. Methods Mol. Biol. 2015:101-111.

Nagashima, M., M. Shiseki, R. M. Pedeux, S. Okamura, M. KitahamaShiseki, K. Miura, J. Yokota, and C. C. Harris. 2003. A novel PHD-finger motif protein, p47ING3, modulates p53-mediated transcription, cell cycle control, and apoptosis. Oncogene 22:343.

Pan, S., W. Chen, X. Liu, J. Xiao, Y. Wang, J. Liu, Y. Du, Y. Wang, and Y. Zhang. 2015. Application of a novel population of multipotent stem cells derived from skin fibroblasts as donor cells in bovine SCNT. PLoS One 10:e0114423.

Perez, S., L. J. Royo, and A. Astudillo. 2007. Identifying the most suitable endogenous control for determining gene expression in hearts from organ donors. BMC Mol. Biol. 8:114.

Qian, L., W. Zhang, B. Lei, A. He, L. Ye, X. Li, and X. Dong. 2016. MicroRNA-101 regulates T-cell acute lymphoblastic leukemia progression and chemotherapeutic sensitivity by targeting Notch1. Oncol. Rep. 36:2511-2516.
Su, J., Y. Wang, Y. Li, R. Li, Q. Li, Y. Wu, F. Quan, J. Liu, Z. Guo, and Y. Zhang. 2011. Oxamflatin significantly improves nuclear reprogramming, blastocyst quality, and in vitro development of bovine SCNT embryos. PLoS One 6:e23805.

Su, J., Y. Wang, X. Xing, L. Zhang, H. Sun, and Y. Zhang. 2015. Melatonin significantly improves the developmental competence of bovine somatic cell nuclear transfer embryos. J. Pineal Res. 59:455-468.

Wakayama, T., A. C. Perry, M. Zuccotti, K. R. Johnson, and R. Yanagimachi. 1998. Full-term development of mice from enucleated oocytes injected with cumulus cell nuclei. Nature 394:369.

Wang, C., S. Lu, J. Jiang, X. Jia, X. Dong, and P. Bu. 2014a. Hsa-microRNA-101 suppresses migration and invasion by targeting Rac1 in thyroid cancer cells. Oncol. Lett. 8:1815-1821.

Wang, L., L. Li, R. Guo, X. Li, Y. Lu, X. Guan, S. C. Gitau, L. Wang, C. Xu, and B. Yang. 2014b. miR-101 promotes breast cancer cell apoptosis by targeting Janus kinase 2. Cell. Physiol. Biochem. 34:413-422.

Wang, M., Y. Gao, P. Qu, S. Qing, F. Qiao, Y. Zhang, J. Mager, and Y. Wang. 2017a. Sperm-borne miR-449b influences cleavage, epigenetic reprogramming and apoptosis of SCNT embryos in bovine. Sci. Rep. 7:13403

Wang, P., X. Li, L. Cao, S. Huang, H. Li, Y. Zhang, T. Yang, J. Jiang, and D. Shi. 2017b. MicroRNA-148a overexpression improves the early development of porcine somatic cell nuclear transfer embryos. PLoS One 12:e180535.

Wang, X., P. Zou, Y. He, K. Meng, F. Quan, and Y. Zhang. 2018. Effect of luteinizing hormone on goat theca cell apoptosis and steroidogenesis through activation of the PI3K/AKT pathway. Anim. Reprod. Sci. 190:108-118

Wang, Y., D. L. Dai, M. Martinka, and G. Li. 2007. Prognostic significance of nuclear ING3 expression in human cutaneous melanoma. Clin. Cancer Res. 13:4111-4116.

Wang, Y. S., S. Tang, Z. X. An, W. Z. Li, J. Liu, F. S. Quan, S. Hua, and Y. Zhang. 2011. Effect of $\mathrm{mSOF}$ and G1.1/G2.2 media on the developmental competence of SCNT-derived bovine embryos. Reprod. Domest. Anim. 46:404-409.

Woods, G. L., K. L. White, D. K. Vanderwall, G.-P. Li, K. I. Aston, T. D. Bunch, L. N. Meerdo, and B. J. Pate. 2003. A mule cloned from fetal cells by nuclear transfer. Science 301:1063.

Zhang, J., P. Qu, C. Zhou, X. Liu, X. Ma, M. Wang, Y. Wang, J. Su, J. Liu, and Y. Zhang. 2017. microRNA-125b is a key epigenetic regulatory factor that promotes nuclear transfer reprogramming. J. Biol. Chem. 292:jbc.M117.796771.

Zheng, H.-B., X.-G. Zheng, and B.-P. Liu. 2015. miRNA-101 inhibits ovarian cancer cells proliferation and invasion by down-regulating expression of SOCS-2. Int. J. Clin. Exp. Med. 8:20263.

Zhou, X., Y. Xia, L. Li, and G. Zhang. 2015. MiR-101 inhibits cell growth and tumorigenesis of Helicobacter pylori related gastric cancer by repression of SOCS2. Cancer Biol. Ther. 16:160-169.

Zou, Y., Z. Jiang, X. Yu, Y. Zhang, M. Sun, W. Wang, Z. Ge, W. De, and L. Sun. 2014. MiR-101 regulates apoptosis of trophoblast HTR-8/SVneo cells by targeting endoplasmic reticulum (ER) protein 44 during preeclampsia. J. Hum. Hypertens. 28:610. 